\title{
Humanity 2.0 - A Healthy Environment for Pregnancy, Business Ethics and The Media
}

\author{
Michael J. Soderling ${ }^{a}$
}

a MD, MBA (Int Dev), Director, Center for Health in Mission, and Co-catalyst, Lausanne Health in Mission Network, USA

This conference convened at the Vatican City on April 19, 2018 by invitation, to address maternal health, business ethics, and the media.

The Humanity 2.0 Forum is a broad spectrum gathering of luminaries and stakeholders at the Vatican to explore a specific impediment to human progress and to discuss courses of action aimed at overcoming it. It is the goal of a Forum to identify one specific venture that has high probability to fundamentally alter human life on earth and then to rally support for a cross sector collaborative venture. ${ }^{1}$

The specific venture identified as being an impediment to human progress for this event was the current state of maternal health for those living in under-resourced parts of the world. It was also pointed out that maternal health indices in the United States are among the lowest within countries considered developed. And for minority groups, African-American moms in particular, statistics are barely better than some "developing" nations.

Opening remarks were given by Marie-Louise Coleiro, President of Malta, the Honorable Linda Lanzillotta, former VP of Senate, Italian Republic, Louis L Bono, Charge d'Affaires, US Embassy to the Holy See, Rabbi Riccardo Di Segni, Chief Rabbi of Rome, and Luca Bergamo, Vice-Mayor of Rome.

\section{Human-centred Civilizations}

The day began with a panel on humancentered civilizations that addressed the topic of tenderness.

Pope Francis in his TED talk in 2017 urged for a "revolution in tenderness." $\mathrm{He}$ reminded us that we are not islands unto ourselves, but rather a common family sharing a common home.

The mission is to encourage a culture of love where we recognize each other's dignity and work selflessly to build a civilization of true opportunity. This exploratory panel will delve more deeply into Pope Francis's remarks and suggest courses of action aimed at realizing the Holy Father's vision. ${ }^{1}$

It was encouraging to hear the panel address the question of "What is tenderness?" I was struck by the variety of responses though none referred to the multiple ways in which Jesus demonstrated tenderness throughout his 3-year ministry on earth. I can think of no greater demonstration of tenderness than Jesus' encounter with the woman at the well or the woman accused of adultery. A fascinating aspect of these two panels was the effort to link the tenderness discussion, with obvious connections to improving the health of pregnant mothers worldwide, with capitalism.

Present within this panel were multiple individuals representing business initiatives that

July 2018. Christian Journal for Global Health, 5(1):47-49. 
promote what one referred to as "consciouscapitalism." Brendan Doherty is co-founder of Forbes Impact that promotes investments that create both financial gain and positive social change. $\mathrm{He}$ stated, "Every investment has an impact whether we acknowledge it or not. The challenge is to transform the economy to create value not only for the shareholders." I believe we will be hearing a great deal more about this attempt to reform capitalism into a system that functions from a dual or even triple bottom line. A dual bottom line gives value to shareholders and creates a social benefit, whereas a triple bottom line also benefits the environment.

\section{Square Roots Lab on Maternal Health}

The final session of the morning was hosted by the organization, Square Roots, founded by Morad Fareed. This time was focused primarily on the crises in maternal health with the most passionate advocate being Jennie Joseph, a midwife working in a rural setting in Florida. She outlined the effective way in which her center had addressed the problem of prematurity and pre-eclampsia in her region through building strong relationships with the pregnant mothers and their families. Joseph was highly critical of the U.S. "healthcare" system, stating that it lets far too many high-risk mothers fall through the cracks, and moms and their babies pay the price. The ultimate price in some cases.

The afternoon sessions kicked off with a large panel of working mothers who discussed the challenges they faced during and after their pregnancies. The panelists were primarily from the U.S. but the U.K. was also represented. The panelists came from very diverse backgrounds including a CNN V.P., an NBC executive, as well as an astronaut who had made two journeys into space. One point that was brought out by the U.K. mothers is how well moms are treated in the UK and Europe in general. Generous maternity leave is provided while the sense in the U.S. is that one is expected to return to work within at least 6 weeks after giving birth. There was also the feeling that the business environment in the U.S. is also not very friendly to moms as they tend to lose their seniority and chance for advancement simply because they took time off to have a child. The U.K. mothers had not had that experience.

The next forum discussed the forthcoming "Lab" that will be developed in Rome to demonstrate how the ideas shared during this forum can be implemented, measured. and shown to be effective.

\section{Power and Pitfalls of Media}

A final panel was led by award-winning journalist Sally Lehrman. Ms. Lehrman leads The Trust Project, an international consortium of news organizations collaborating to use transparency to build a more trustworthy and trusted press. This initiative is hosted by Santa Clara University's Markkula Center for Applied Ethics. This panel discussed the present situation facing the media in today's environment of "fake news." I did not hear an explanation of how this ties into the overall theme of the day but the panel discussion was a fascinating one.

There is great concern amongst many in the media today regarding the perceived, and probably justified, public opinion that fewer and fewer news media outlets are trustworthy. This attitude creates challenges for those who are trustworthy sources of news, the greatest being, quite possibly, that it threatens their very existence. If the public lumps all news sources into one category, not reliable to tell the truth, then those who are expending valuable resources to be trustworthy may not survive in this new online environment where all news is expected to be offered at no cost to the consumer.

This project is engaging many of the major players such as Facebook, Bing, Google, and Twitter. Attempts are being made to create the means by which a consumer can explore an online article to discover its trustworthiness. One example would be to provide a way in which the reader could explore

July 2018. Christian Journal for Global Health, 5(1):47-49. 
the background of the articles author. A link could be in place so that when clicking on the author's picture, it will direct one to a location containing all the necessary information about that author. It is hoped that AI will assist in creating a system whereby the reader can easily be reassured that what is written is reliable.

\section{Reflections}

Overall, this was a most interesting event. It occurs to this author that this represents a reaction, in a sense, to modernism and post-modernism (and post-post modernism or even metamodernism!). As religion has been increasingly marginalized and deemed irrelevant, secular-humanism has tried to fill the cultural void leftover and has been found wanting. There is little to no meaning in life if the secular-humanist religion is to be believed and pursued. And thus, the capitalism that results from this shift has been found to be lacking any heart or soul and is seen as being a system that only cares about short-term gain and shareholder income. So, we had wonderful discussions on the theme of tenderness, and how that concept can be applied to big business, and how that could create a social good and even perhaps have a positive effect on the environment. As funding for initiatives led by followers of Jesus dry up, this current movement toward conscious-capitalism could be very beneficial so long as we can convince the investors that we are engaged in something that potentially benefits all of humanity and are doing our work with the highest of standards and are measuring our outcomes.

\section{References}

1. Humanity 2.0 - A shared horizon for humanity. Available from: https://humanity2-0.org/

Competing Interests: None declared.

Correspondence: Michael Soderling. Center for Health in Mission. mjsoderling@gmail.com

Cite this article as: Soderling MJ. Humanity 2.0 - A healthy environment for pregnancy. Christian Journal for Global Health. July 2018; 5(1):47-49. https://doi.org/10.15566/cjgh.v5i1.219

(C) Soderling MJ. This is an open-access article distributed under the terms of the Creative Commons Attribution License, which permits unrestricted use, distribution, and reproduction in any medium, provided the original author and source are properly cited. To view a copy of the license, visit https://creativecommons.org/licenses/by/4.0/

www.cjgh.org

July 2018. Christian Journal for Global Health, 5(1):47-49. 